\title{
Photocatalytic properties of zirconium oxide-zinc oxide nanoparticles synthesised using microwave irradiation
}

\author{
Olga Długosz ${ }^{1}\left[{ }^{10} \cdot\right.$ Krzysztof Szostak $^{1} \cdot$ Marcin Banach $^{1}$
}

Received: 2 August 2019 / Accepted: 27 August 2019 / Published online: 6 September 2019

(C) The Author(s) 2019

\begin{abstract}
$\mathrm{ZrO}_{2}-\mathrm{ZnO}$ nanoparticles with different mass concentrations of $\mathrm{ZrO}_{2}(1 \%, 5 \%, 10 \%, 20 \%)$ were prepared using a two-stage precipitation method with microwave irradiation. The $\mathrm{ZrO}_{2}-\mathrm{ZnO}$ with $10 \%$ of $\mathrm{ZrO}_{2}$ had the highest photocatalytic activity. The obtained material was characterised using XRD, which confirmed a high crystal structure in the synthesised material, and transmission electron microscopy (TEM) analysis, which depicted that micro and nano needle-shaped particles had been obtained and that irregularly shaped nanoparticles were present on the surface of those particles. TEM-EDX analysis confirmed the presence of both $\mathrm{ZnO}$ and $\mathrm{ZrO}_{2}$ in the product. FT-IR analyses showed that the positions of peaks related to $\mathrm{Zn}-\mathrm{O}$ and $\mathrm{Zr}-\mathrm{O}$ absorption bands did not change in $\mathrm{ZrO}_{2}-\mathrm{ZnO}$ NPs. The initial concentration of Methylene Blue (MB), the $\mathrm{pH}$ of the solution, and the mass of the photocatalyst were investigated to determine the photocatalytic efficiency of the material and the degree of removal of the MB. The highest efficiency (97\%) was obtained in the following conditions: $30 \mathrm{mg} /$ $\mathrm{dm}^{3}$ of the MB solution, $\mathrm{pH} 9$ and $70 \mathrm{mg} \mathrm{ZrO}_{2}-\mathrm{ZnO}$ after 30 min of reaction time under UV irradiation.
\end{abstract}

Keywords Zinc oxide $\cdot$ Zirconium oxide $\cdot$ Nanoparticles $\cdot$ Photocatalytic properties $\cdot$ Methylene Blue $\cdot$ Microwave irradiation

\section{Introduction}

Oxide semiconductor nanomaterials are gaining increasing interest due to their attractive functional properties related to their small particle size and hence large active surface (Dal Santo et al. 2018; Sowik et al. 2019). Among these features, the photocatalytic properties are of particular interest. This is due to the fact that these kinds of nanomaterials can be used in many fields such as wastewater treatment or coating materials (Ruiz-Hitzky et al. 2019).

Zinc oxide, especially on a nanometric scale, is a low cost, environmentally friendly with potentially high photocatalytic properties (Lakshmi et al. 2012; Lu et al. 2017). $\mathrm{ZnO}$ has a broader energy gap $(3.2 \mathrm{eV})$ compared to $\mathrm{TiO}_{2}$, which directly contributes to lower photocatalytic activity (Nagao et al. 2016). The modification of the structure of $\mathrm{ZnO}$ nanoparticles (ZnO NPs) with the addition of metal and

Olga Długosz

odlugosz@chemia.pk.edu.pl

1 Faculty of Chemical Engineering and Technology, Institute of Chemistry and Inorganic Technology, Cracow University of Technology, Warszawska 24, 31-155 Cracow, Poland metal oxide nanoparticles affects the distance between the conduction band and the valance band, which may improve the photocatalytic properties of the material (Karuppaiah et al. 2019).

The main limitations of the photocatalytic properties of $\mathrm{ZnO}$ nanoparticles are the relatively broad energy gap and the rapid recombination of electron-hole pairs, which limits the photocatalytic activity of ZnO NPs. It has been noted that the addition of metal oxides improves the photocatalytic properties of, among others, $\mathrm{ZnO}, \mathrm{TiO}_{2}, \mathrm{MgO}, \mathrm{WO}_{3}$ and $\mathrm{SnO}_{2}$ in both UV and visible light (Thirumalai et al. 2017; Reszczyńska et al. 2015; Al-Hamdi et al. 2015; Kokorin et al. 2018). One material that enhances the photocatalytic properties of $\mathrm{ZnO} N P s$ is zirconium oxide $\left(\mathrm{ZrO}_{2}\right)$.

Zirconium oxide belongs to the group of semiconductor materials. It usually occurs in an amorphous form with a relatively wide energy gap [ 5.25 eV (Oluwabi et al. 2018)]. Pure $\mathrm{ZrO}_{2}$ has very limited photocatalytic properties, but the addition of the oxide in the other oxides, including $\mathrm{TiO}_{2}$, $\mathrm{SnO}_{2}, \mathrm{ZnO}$ has beneficial effect on their photocatalytic activity (Aghabeygi et al. 2017; Pirzada et al. 2015). One of the mechanisms to improve properties of photocatalytic oxides is the modification their structure by creating numerous 
surface defects, developing the surface of the deposition of other oxide nucleation, thus supporting the electron transfer processes accompanying the photocatalytic process (Uribe López et al. 2019). In the case of the $\mathrm{ZrO}_{2}-\mathrm{ZnO}$ system, in a two-stage process, $\mathrm{ZnO}$ particles are obtained on the surface of the amorphous $\mathrm{ZrO}_{2}$ particles, which may have a different structure than those obtained in a single-stage process (Ibrahim 2015). Additionally, the structure of $\mathrm{ZrO}_{2}$ plays an important role in the reduction of the electron-hole recombination of doped systems (Gurushantha et al. 2017). The replacement of $\mathrm{Zn}^{2+}$ with $\mathrm{Zr}^{4+}$ disturbs the charge balance. The disturbed charge balance contributes to the adsorption of more hydroxide ions at the catalyst surface, which additionally blocks the recombination of electron-hole pairs (Karuppaiah et al. 2019). Aghabeygi and Khademi-Shamami (2018) investigated $\mathrm{ZnO} / \mathrm{ZrO}_{2}$ nanocomposites prepared with ultrasonic irradiation. The $\mathrm{ZnO}$ nanocomposite was excited by the transfer of the electrons promoted from the conduction band of $\mathrm{ZnO}-\mathrm{ZrO}_{2}$ and simultaneously transferred the holes from the valence band of $\mathrm{ZrO}_{2}$ to the $\mathrm{ZnO}$.

There are known methods for obtaining zinc oxide nanoparticles modified by $\mathrm{ZrO}_{2}$ or other compounds. The great limitations in the proposed tests are the long time of the photodegradation process and the low concentration of dyes used in the processes. Sapawe et al. received $\mathrm{ZnO}-\mathrm{ZrO}_{2}-\mathrm{HY}$ zeolite nanocomposite, for the removal of Methylene Blue. The dye removal efficiency was $99.7 \%$, but the dye concentration was $10 \mathrm{mg} / \mathrm{dm}^{3}$, and the process was carried out for $90 \mathrm{~min}$ (Sapawe et al. 2013). Chen et al. obtained $\mathrm{ZnO}$ modified with $\mathrm{SnO}_{2}$ nanoparticles to remove various dye wastewaters. By increasing the initial concentration of Congo Red from 20 to $40 \mathrm{ppm}$, the photodegradation time increased from 40 to $80 \mathrm{~min}$ while reducing the efficiency from 96.8 to $89.3 \%$ (Chen et al. 2015). These are the reasons why it is necessary to dilute the dye solution, use larger masses of photocatalyst or extend the processing time.

Metal oxide nanoparticles can be obtained by hydrothermal processes usually carried out by several hours. Qui et al. they received doped $\mathrm{ZrO}_{2}-\mathrm{ZnO}$ photocatalyst; however, the process was carried out under pressure reactor for $12 \mathrm{~h}$ (Qiu et al. 2018). Aghabygi and Khademi-Shamami developed an alternative method of obtaining $\mathrm{ZnO} / \mathrm{ZrO}_{2}$ nanocomposite using ultrasound, but after $30 \mathrm{~min}$ of ultrasonication, the material was calcined (Aghabeygi and Khademi-Shamami 2018). Insertion of the energy into the system using microwave radiation reduces the synthesis time. In addition, the amount of energy in the process allows obtaining products with a high degree of crystallinity, so that the calcining process can be omitted.

This study aimed to prepare $\mathrm{ZrO}_{2}-\mathrm{ZnO}$ nanoparticles using a precipitation method with microwave irradiation. The photocatalytic properties of the obtained material were investigated for the degradation of Methylene Blue (MB) solution under UV irradiation. The effects of the mass concentration of $\mathrm{ZrO}_{2}$ in $\mathrm{ZnO}-\mathrm{ZrO}_{2} \mathrm{NPs}$, the initial concentration of $\mathrm{MB}$, the $\mathrm{pH}$ of the solution, and the mass of photocatalyst were investigated.

\section{Experimental}

\section{Materials}

Zinc sulphate $\mathrm{ZnSO}_{4} \cdot 5 \mathrm{H}_{2} \mathrm{O}$ (Sigma Aldrich), zirconyl chloride $\mathrm{ZrOCl}_{2} \cdot 8 \mathrm{H}_{2} \mathrm{O}$ (Sigma Aldrich) and sodium carbonate $\mathrm{Na}_{2} \mathrm{CO}_{3}$ (Sigma Aldrich) were used in the synthesis of the photocatalytic material. MB was purchased from Sigma Aldrich and used to study the photocatalytic properties of $\mathrm{ZrO}_{2}-\mathrm{ZnO}$. All chemicals were of analytical grade and were used without further purification.

\section{Synthesis of $\mathrm{ZrO}_{2}-\mathrm{ZnO}$}

A precipitation method was used to produce $\mathrm{ZrO}_{2}-\mathrm{ZnO}$. Two-step synthesis was carried out in a microwave reactor. First, $\mathrm{Zr}(\mathrm{OH})_{4}$ was synthesised by mixing $20 \mathrm{ml} 1 \mathrm{M}$ $\mathrm{ZrOCl}_{2} \cdot 8 \mathrm{H}_{2} \mathrm{O}$ with $20 \mathrm{ml} 2 \mathrm{M} \mathrm{Na}_{2} \mathrm{CO}_{3}$. The suspension was transferred to a Teflon vessel and it was heated in a MAGNUM II microwave reactor (Ertec, Poland) for $10 \mathrm{~min}$ at $150{ }^{\circ} \mathrm{C}$. The obtained zirconium oxide(IV) was filtered and dried at $70{ }^{\circ} \mathrm{C}$ for $24 \mathrm{~h}$. In the next step, solid $\mathrm{ZrO}_{2}$ nanoparticles in an amount corresponding to fixed percentage composition, $20 \mathrm{ml}$ of $1 \mathrm{M} \mathrm{ZnSO}_{4} \cdot 5 \mathrm{H}_{2} \mathrm{O}$ and $10 \mathrm{ml}$ of $2 \mathrm{M} \mathrm{Na}_{2} \mathrm{CO}_{3}$ were added to the beaker. After mixing, the suspension was transferred to a Teflon vessel and heated in the microwave reactor for $10 \mathrm{~min}$ at $180^{\circ} \mathrm{C}$. The obtained product was filtered and dried at $70{ }^{\circ} \mathrm{C}$ for $24 \mathrm{~h}$. The effect of the $\mathrm{ZrO}_{2}$ mass on the photocatalytic properties of the final product was also established.

\section{Instrumental analysis}

The structure of $\mathrm{ZrO}_{2}-\mathrm{ZnO}$ before and after the photocatalytic reaction was examined using transmission electron microscopy (TEM) with energy dispersive X-ray analysis (EDX) and elemental mapping using a Tecnai Transmission Electron Microscope, F20 X-Twin, FEI Europe. The Fourier Transform Infrared Spectroscopy (FTIR) method (Nicolet 380) was helpful for determining the degree of sorption of the dye as well as its decomposition under the influence of UV. XRD analysis (Philips X'Pert camera with monochromator PW 1752/00 $\mathrm{CuK} \alpha$ ) determined the degree of crystallinity of $\mathrm{ZrO}_{2}, \mathrm{ZnO}$ and $\mathrm{ZrO}_{2}-\mathrm{ZnO}$. 


\section{Optical studies}

The spectrum of MB and its concentration were examined by UV-Vis spectroscopy (Rayleigh UV-1800 spectrophotometer). The calibration curve was prepared at $664 \mathrm{~nm}$ and was made in triplicate (Fig. 1).

The absorption, which corresponds to the energy difference between the top of the valence band and the bottom of the conduction band, is defined to designate the band gap using the UV-Vis method (Mexicana De Física et al. 2007). The value of the band gap $\left(E_{\mathrm{g}}\right)$ energy was obtained using the following equation:

$E_{\mathrm{g}}=\frac{h \cdot c \cdot 10^{19}}{\lambda \cdot 1.6}[\mathrm{eV}]$

where $h$-Planks constant $=6.626 \cdot 10^{-34} \mathrm{~J} \mathrm{~s}, c$ - speed of light $=3.0 \cdot 10^{8} \mathrm{~m} / \mathrm{s}, \lambda$ —ut off wavelength/absorption edge in $\mathrm{nm}$.

\section{Photocatalytic degradation experiments}

The photodegradation of $\mathrm{MB}$ using $\mathrm{ZrO}_{2}-\mathrm{ZnO}$ was studied using batch mode experiments. This was done by studying the effect of initial concentration of dye, material dose and $\mathrm{pH}$ of the solution. The photocatalytic activities of the

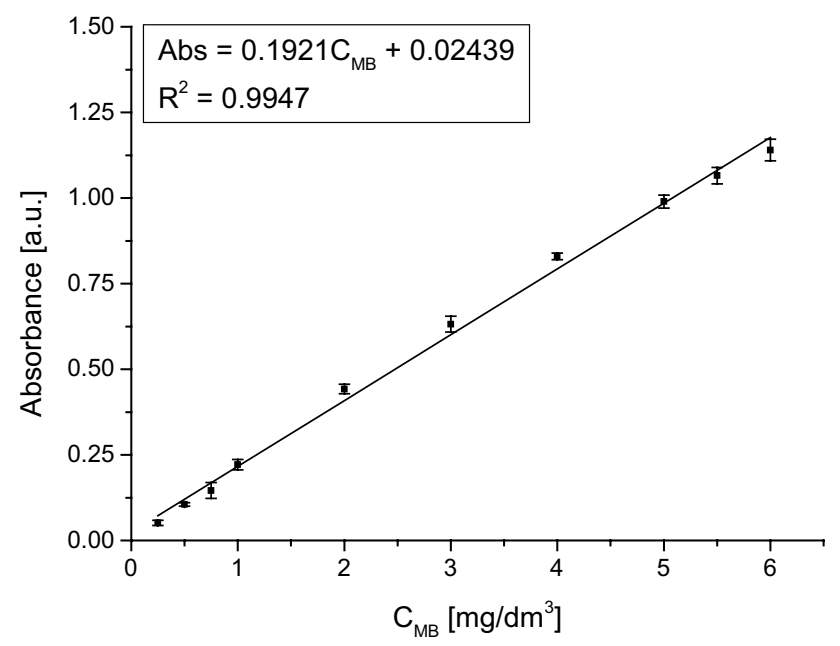

Fig. 1 Calibration curve for MB absorption at $664 \mathrm{~nm}$ photocatalyst were investigated by measuring the degradation of MB aqueous solutions under UV light irradiation using a UV lamp (wavelength $360 \mathrm{~nm}$ ). A certain amount of the material was added while mixing $30 \mathrm{ml}$ of the solution of dye with a magnetic stirrer for a specified period of time. The amounts of the degraded dye $R_{\mathrm{D}}(\mathrm{mg} / \mathrm{g})(2)$ and efficiency of photocatalytic degradation of MB (3) were calculated from the following dependences:

$R_{\mathrm{D}}(\mathrm{mg} / \mathrm{g})=\frac{\left(C_{0}-C_{t}\right) V}{m}$,

$E(\%)=\frac{\left(C_{0}-C_{t}\right)}{C_{0}} \cdot 100$,

where $C_{0}$ and $C_{t}$ are the initial and final concentrations of the dye solution $\left(\mathrm{mg} / \mathrm{dm}^{3}\right)$ at time $t, V$ is the solution volume $\left(\mathrm{dm}^{3}\right)$, and $m$ is the mass of the material $(\mathrm{g})$.

\section{Statistical analysis}

The initial concentration of the dye was tested using a UV-Vis spectrophotometer in the range of $20-60 \mathrm{mg} / \mathrm{dm}^{3}$. The effect of the mass of the photocatalytic deposit was examined in the range of $10-50 \mathrm{mg}$ and the effect of the $\mathrm{pH}$ of the solution was tested in the range from 3 to 11 . The $\mathrm{pH}$ of the solution was adjusted with $15 \% \mathrm{HNO}_{3}$ or $0.1 \mathrm{M}$ $\mathrm{NaOH}$. A central composite design (CCD) plan was used to examine the effect of parameters on the photocatalysis process and determine the most favourable parameter values (Table 1). As the output parameters, the degree of dye removal per $1 \mathrm{~g}$ of the deposit and photodegradation efficiency were used. The research results were developed using the program STATISTICA (version 10.0).

\section{Results and discussion}

\section{Selection of the final deposit based on the photocatalytic activity of the product}

In the first stage, to obtain the material with the highest photocatalytic efficiency, the most favourable mass concentration of $\mathrm{ZrO}_{2}$ in the $\mathrm{ZrO}_{2}-\mathrm{ZnO}$ nanoparticles was determined. For this purpose, a various mass of $\mathrm{ZrO}_{2}$ powder and
Table 1 Experimental range and levels of independent process variables

\begin{tabular}{lllllllll}
\hline Variable & & Unit & Notation & Range \\
\cline { 5 - 8 } & & & & $-\alpha(-1.68)$ & $(-1)$ & $(0)$ & $(1)$ & $+\alpha(+1.68)$ \\
\hline Initial concentration of $\mathrm{MB}$ & $C_{0}$ & $\left(\mathrm{mg} / \mathrm{dm}^{3}\right)$ & $x_{1}$ & 23.18 & 30 & 40 & 50 & 56.82 \\
$\mathrm{pH}$ & $\mathrm{pH}$ & $(-)$ & $x_{2}$ & 3.64 & 5 & 7 & 9 & 10.36 \\
Photocatalyst mass & $m$ & $(\mathrm{~g})$ & $x_{3}$ & 16.36 & 30 & 50 & 70 & 83.64 \\
\hline
\end{tabular}


a constant volume of $\mathrm{ZnSO}_{4}$ and $\mathrm{Na}_{2} \mathrm{CO}_{3}$ solutions were added to the beaker. The mixture was transferred to a Teflon vessel and heated using microwave irradiation for $10 \mathrm{~min}$ at $180{ }^{\circ} \mathrm{C}$. After the process, the product was filtered, washed and dried. The photodegradation efficiency and the amount of degraded dye of $\mathrm{ZrO}_{2}-\mathrm{ZnO}$ with a mass concentration of $\mathrm{ZrO}_{2}$ equalling $1 \%, 5 \%, 10 \%$ and $20 \%$ are presented in Fig. 2. The efficiency of pure $\mathrm{ZnO}$ and $\mathrm{ZrO}_{2}$ nanoparticles is also shown. Each material was tested in darkness and in UV light in triplicate. The results of the photocatalytic and sorption studies were used to compare the properties of each deposit.

$\mathrm{ZrO}_{2}-\mathrm{ZnO}$ with $10 \% \mathrm{ZrO}_{2}$ showed the highest photocatalytic activity compared to materials with different concentrations of $\mathrm{ZrO}_{2}$. A further increase in the concentration of $\mathrm{ZrO}_{2}$ increased the sorption capacity of the material but reduced photocatalytic properties, which was undesirable (Fig. 2).

On the basis of the conducted photodegradation studies of $\mathrm{MB}$ on pure $\mathrm{ZrO}_{2}$, an increase in absorbance at a wavelength of $664 \mathrm{~nm}$ was observed during the reaction time of irradiation. Higher absorbance of the solution indicates an increase in the concentration of the dye in the solution. The study of the kinetics of the sorption process confirmed the high impact of physical sorption on the process (Table 2).
The second-order model is a model with the highest determination coefficient, which suggests the chemical nature of sorption. Based on the analysis of the process carried out under UV, the desorption process took place. The secondorder model, despite a much lower value of the reaction rate constant is still positive, which would indicate a slow sorption process. In the case of the first-order model, the determination coefficient is lower, especially in the case of the UV process. However, the reaction rate constant is negative, which confirms the desorption process. Both models show some disadvantages in the actual description of the sorption process on $\mathrm{ZrO}_{2}$, hence the complex mechanism of the process, combining the dye with the material, both by chemical and physical interactions. The process of desorption under the influence of UV is not yet known, therefore, further research should be carried out.

The constant of the reaction rate in the pseudo-first-order model in the process conducted with UV radiation has a negative value, which confirmed the desorption process. In all kinetic models, the degree of regression fit of experimental data to model equations is high, which suggests a complex process of physical sorption combined with chemical sorption. According to the results, after the first minute of irradiation with UV radiation, an increase in the concentration of MB in the solution was observed (Fig. 3).
Fig. 2 Photocatalytic efficiency of $\mathrm{ZrO}_{2}-\mathrm{ZnO}$ with percentage concentrations of $\mathrm{ZrO}_{2}$ from 0 to $20 \%$ wt
Table 2 Kinetic parameters of $\mathrm{MB}$ adsorption onto $\mathrm{ZrO}_{2}$ in darkness and in UV light

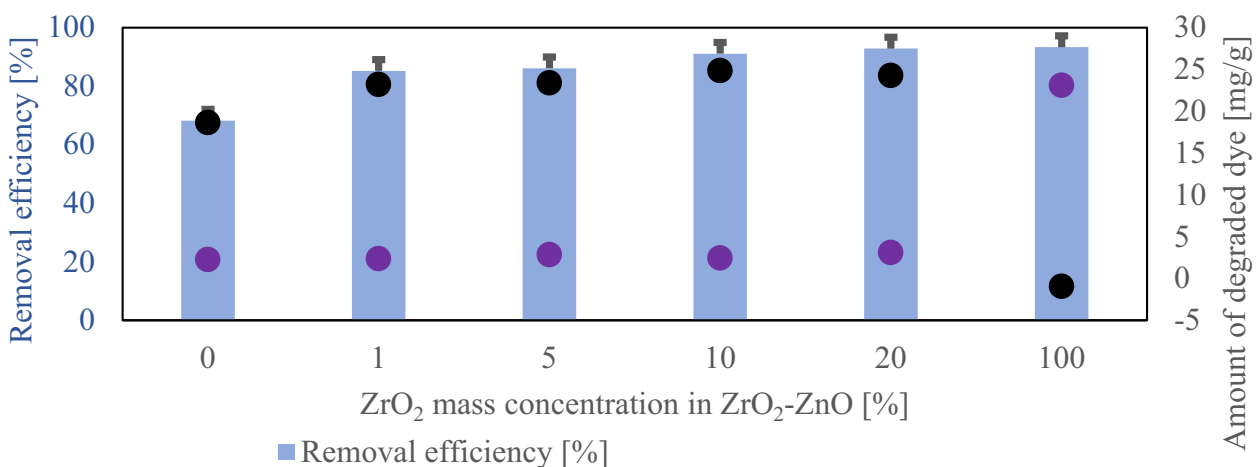

- Amount of degraded dye during photodegradation [mg/g]

- Amount of adsorbed dye [mg/g]

\begin{tabular}{llll}
\hline Kinetic model & Parameters & Sorption in the darkness & Sorption under UV \\
\hline First order kinetic model & $k_{\mathrm{I}}\left(\mathrm{min}^{-1}\right)$ & $0.1181 \pm 0.05134$ & $-0.02487 \pm 0.003306$ \\
& $R_{\mathrm{Dmax}}(\mathrm{mg} / \mathrm{g})$ & $5.9265 \pm 1.1720$ & $0.9112 \pm 0.8889$ \\
& $R^{2}$ & 0.9519 & 0.7281 \\
Second order kinetic model & $k_{\mathrm{II}}(\mathrm{g} / \mathrm{mg} / \mathrm{min})$ & $0.06232 \pm 0.004051$ & $1.386 \cdot 10^{-3} \pm 2.985 \cdot 10^{-4}$ \\
& $R_{\text {Dmax }}(\mathrm{mg} / \mathrm{g})$ & $28.9855 \pm 0.2198$ & $25.8398 \pm 0.3849$ \\
& $R^{2}$ & 0.9998 & 0.9991 \\
Elovich & $\beta(\mathrm{g} / \mathrm{mg})$ & $0.5304 \pm 0.03424$ & $0.6910 \pm 0.1976$ \\
& $R^{2}$ & 0.9836 & 0.7535 \\
Experimental data & $R_{\text {Dexp }}(\mathrm{mg} / \mathrm{g})$ & 28.5712 & 26.9068 \\
\hline
\end{tabular}

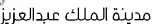
KACST 

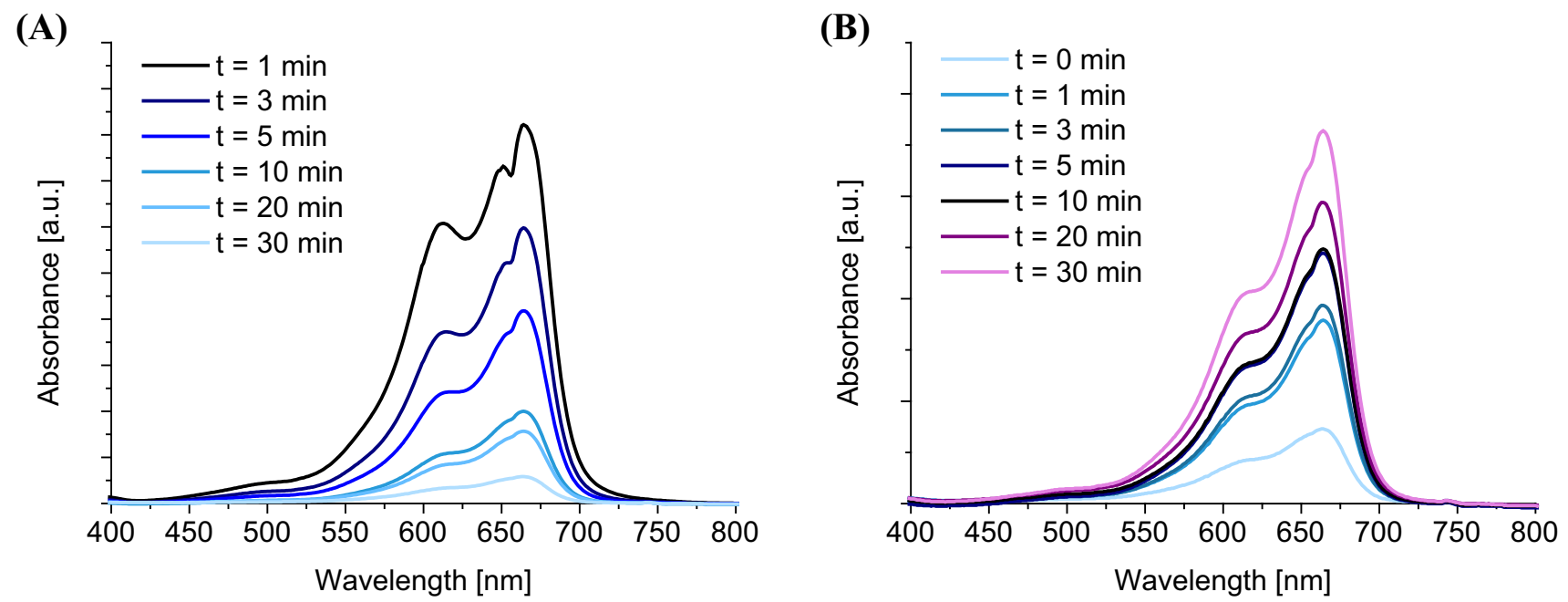

Fig. 3 Absorption spectra of $\mathrm{MB}$ solution in sorption onto $\mathrm{ZrO}_{2}$ in darkness (a) and under UV irradiation (b)

The surface energy of adsorption decreases with increasing temperature. In the case of UV radiation, the energy added to the system may increase the energy of the MB particles and thus reduce the surface energy between the dye particles and the $\mathrm{ZrO}_{2}$ surface. With a significant contribution of physical sorption, the energy of the bond between the bed and the dye is lower compared to chemical sorption. Therefore, after providing additional energy in the form of UV radiation, MB particles can be desorbed (Fig. 4).

Additionally, for the obtained materials, the width of the energy gap was determined (Table 3). A higher mass ratio of $\mathrm{ZrO}_{2}$ in $\mathrm{ZrO}_{2}-\mathrm{ZnO}$ materials caused a decreased width in the energy gap. The width of the energy gap for each material was obtained using the UV-Vis method. Absorption, which corresponds to the energy difference between the top of the valence band and the bottom of the conduction band, was used to designate the band gaps (Fig. 5). Based on the studies, material with $10 \%$ wt $\mathrm{ZrO}_{2}$ was chosen as the material for further analysis.

\section{Photocatalytic degradation of dye solutions}

\section{Effects of parameters processes}

A CCD with three factors and five coded levels was adopted in the optimization study. Table 4 presents the
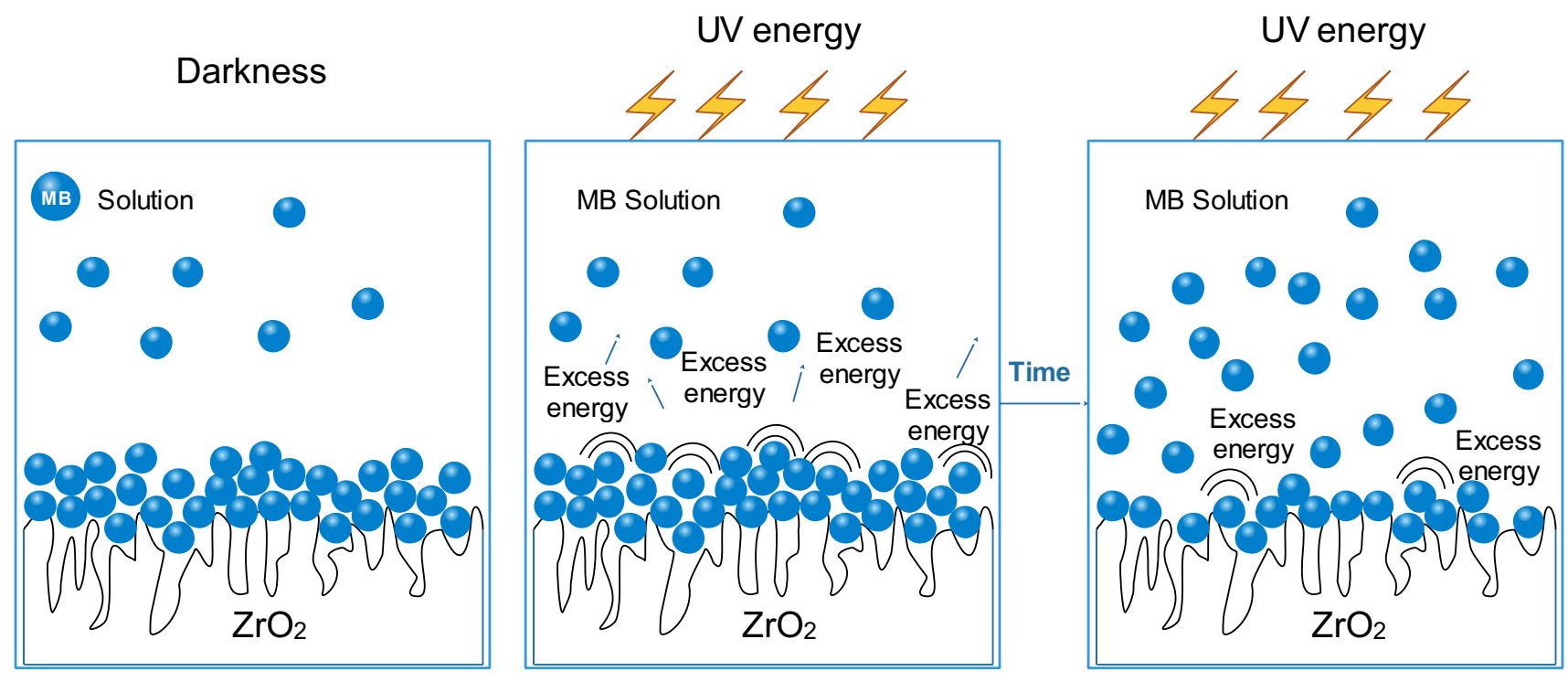

Fig. 4 Desorption mechanism for the $\mathrm{MB}-\mathrm{ZrO}_{2}$ system resulting from UV irradiation 
Table 3 Width of band gap for $\mathrm{ZnO}$ with $\mathrm{ZrO}_{2}$

\begin{tabular}{llccc}
\hline Sample & Width of band gap $(\mathrm{eV})$ & $\begin{array}{l}\text { Photodegradation of } \\
\text { the dye }(\mathrm{mg} / \mathrm{g})\end{array}$ & $\begin{array}{l}\text { Dye reduction in the } \\
\text { darkness }(\mathrm{mg} / \mathrm{g})\end{array}$ & $\begin{array}{c}\text { The contribution of sorption in } \\
\text { the dye degradation process }(\%)\end{array}$ \\
\hline $\mathrm{ZnO}$ & $3.18 \pm 0.02$ & $16.38 \pm 0.49$ & $2.25 \pm 0.31$ & $12.09 \pm 0.49$ \\
$\mathrm{ZnO}-\mathrm{ZrO}_{2}(1 \%)$ & $3.19 \pm 0.02$ & $20.84 \pm 0.26$ & $2.37 \pm 0.19$ & $10.20 \pm 0.28$ \\
$\mathrm{ZnO}-\mathrm{ZrO}_{2}(5 \%)$ & $3.18 \pm 0.01$ & $20.55 \pm 0.23$ & $2.84 \pm 0.94$ & $12.14 \pm 0.72$ \\
$\mathrm{ZnO}-\mathrm{ZrO}_{2}(10 \%)$ & $3.17 \pm 0.01$ & $22.39 \pm 0.18$ & $2.46 \pm 0.19$ & $9.89 \pm 0.23$ \\
$\mathrm{ZnO}-\mathrm{ZrO}_{2}(20 \%)$ & $3.17 \pm 0.02$ & $22.19 \pm 0.03$ & $3.09 \pm 0.46$ & $12.21 \pm 0.30$ \\
$\mathrm{ZrO}$ & $\sim 5.25$ (Oluwabi et al. 2018) & $-1.05 \pm 0.42$ & $23.10 \pm 0.15$ & $100.0 \pm 0.35$ \\
\hline
\end{tabular}

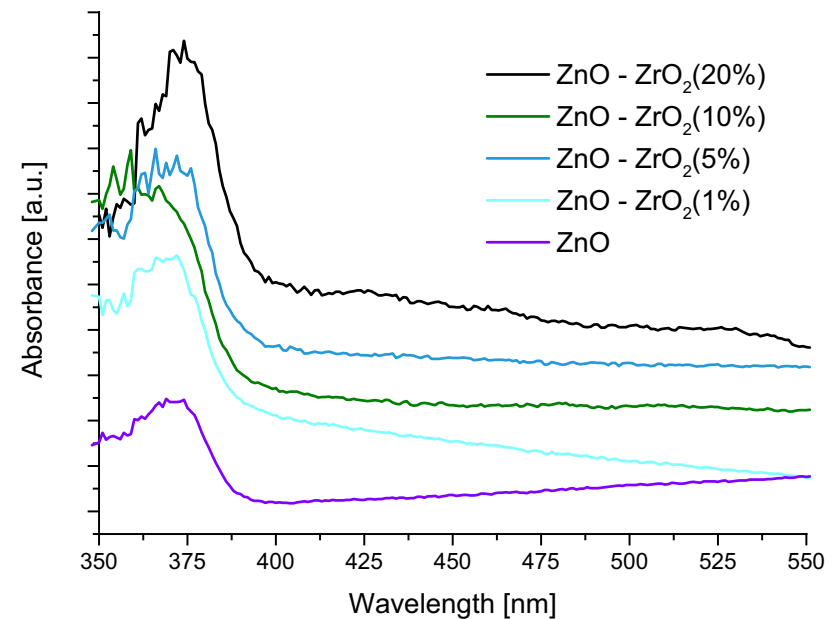

Fig. 5 Optical absorption edge determination for $\mathrm{ZrO}_{2}-\mathrm{ZnO}$ with different concentration of $\mathrm{ZrO}_{2}$

experimental values of the photocatalytic efficiency of MB degradation and the amounts of the degraded dye under designed conditions. The response variable was fitted using a regression model:

$y=a_{0}+\sum_{i=1}^{k} a_{i} \cdot x_{i}+\sum_{i=1}^{k} a_{i i} \cdot x_{i}^{2}+\sum_{i<j}^{k} a_{i j} \cdot x_{i} \cdot x_{j}$,

where $y$-efficiency of photodegradation (\%), $a_{0}$-constant term, $a_{i}$-linear coefficients, $a_{i i}$-quadratic coefficients, $a_{i j}$ - coefficient of the interaction parameters, $x_{i}, x_{j}$-values of the independent variables.

Based on the ANOVA results, parameters that significantly affected the photocatalytic efficiency of $\mathrm{ZrO}_{2}-\mathrm{ZnO}$ were determined (Table 5). All selected input variables as well as their interactions had a significant effect on the photocatalytic properties of the material. The $p$ value of 0.05 was determined as the significance level in the analysis.

The increase in the gradient between the amount of $\mathrm{ZrO}_{2}-\mathrm{ZnO}$ and the dye in the system contributed to the
Table 4 Experimental results of the $\mathrm{CCD}$ plan for the $\mathrm{ZrO}_{2}-\mathrm{ZnO}$ photocatalytic process

\begin{tabular}{llllll}
\hline Lp. & $C_{0}\left(\mathrm{mg} / \mathrm{dm}^{3}\right)$ & Mass $(\mathrm{mg})$ & $\mathrm{pH}(-)$ & $E(\%)$ & $R_{\mathrm{D}}(\mathrm{mg} / \mathrm{g})$ \\
& $x_{1}$ & $x_{2}$ & $x_{3}$ & $y_{1}$ & \multicolumn{1}{l}{$y_{2}$} \\
\hline 1 & 30 & 30 & 5 & 62.77 & 20.12 \\
2 & 30 & 70 & 5 & 66.03 & 8.98 \\
3 & 30 & 30 & 9 & 86.99 & 28.12 \\
4 & 30 & 70 & 9 & 97.15 & 13.24 \\
5 & 50 & 30 & 5 & 54.89 & 28.74 \\
6 & 50 & 70 & 5 & 63.49 & 14.48 \\
7 & 50 & 30 & 9 & 67.40 & 35.66 \\
8 & 50 & 70 & 9 & 90.64 & 20.70 \\
9 & 23.18 & 50 & 7 & 95.63 & 13.91 \\
10 & 56.82 & 50 & 7 & 79.67 & 28.69 \\
11 & 40 & 50 & 3.64 & 70.78 & 17.14 \\
12 & 40 & 50 & 10.38 & 91.15 & 22.47 \\
13 & 40 & 16.36 & 7 & 64.59 & 48.29 \\
14 & 40 & 83.64 & 7 & 96.14 & 14.05 \\
15 & 40 & 50 & 7 & 88.16 & 21.62 \\
16 & 40 & 50 & 7 & 88.95 & 21.75 \\
\hline
\end{tabular}

increase in the removal rate of $\mathrm{MB}$ from the solution, which is associated with an increase in driving force. The initial concentration of the dye as a factor with a negative coefficient estimate caused a decrease in the efficiency of the $\mathrm{ZrO}_{2}-\mathrm{ZnO}$ together with an increase in the concentration of dye in the system (Fig. 6). Lee et al. studied the effect of various factors on $\mathrm{ZnO}$ efficiency, also confirming the negative effect of the initial concentration of dye and a positive coefficient estimate of the $\mathrm{pH}$ of the solution on the degradation of phenoxyacetic acid (Lee et al. 2015).

Effect of initial dye concentration on photocatalytic performance The photocatalytic degradation of MB was carried out at different initial concentrations of dye in the range of $20-60 \mathrm{mg} / \mathrm{dm}^{3}$. The results are shown in Fig. 7. An increase in the concentration of dye decreases the path length of photons entering the pollutant solution. At high pollutant concentrations, a significant amount of light may be absorbed 
Table 5 Coefficient of regression model and its significance on deposit efficiency (\%) and dye removal rate (mg/g)

\begin{tabular}{|c|c|c|c|c|c|c|c|c|}
\hline \multirow[t]{2}{*}{ Independent variables } & \multirow[t]{2}{*}{ Symbol } & \multicolumn{4}{|l|}{$E(\%)$} & \multicolumn{3}{|l|}{$R_{\mathrm{D}}(\mathrm{mg} / \mathrm{g})$} \\
\hline & & Coefficient estimate & Std. deviation & $F$ value & $p$ value & Coefficient estimate & Std. deviation & $F$ value $p$ value \\
\hline Mean/constant & & 89.41 & 0.3957 & 62.40 & 0.0028 & 21.97 & 0.0665 & $330.4 \quad 0.0019$ \\
\hline (1) $C_{0}\left[\mathrm{mg} / \mathrm{dm}^{3}\right](L)$ & $x_{1}$ & -15.61 & 0.5109 & -30.55 & 0.0208 & 13.30 & 0.0859 & $\begin{array}{ll}154.9 & 0.0041\end{array}$ \\
\hline$C_{0}\left[\mathrm{mg} / \mathrm{dm}^{3}\right](Q)$ & $x_{1}^{2}$ & -13.63 & 1.043 & -13.07 & 0.0486 & -4.705 & 0.1753 & -26.840 .0237 \\
\hline (2) $m[\mathrm{mg}](L)$ & $x_{2}$ & 24.21 & 0.5109 & 47.39 & 0.0134 & -27.79 & 0.0859 & -323.70 .0020 \\
\hline$m[\mathrm{mg}](Q)$ & $x_{2}^{2}$ & -28.21 & 1.043 & -27.05 & 0.0235 & 15.04 & 0.1753 & 85.780 .0074 \\
\hline (3) $\mathrm{pH}[-](L)$ & $x_{3}$ & 31.85 & 0.5107 & 62.36 & 0.0102 & 8.467 & 0.0858 & 98.640 .0065 \\
\hline $\mathrm{pH}[-](Q)$ & $x_{3}^{2}$ & -27.00 & 1.043 & -25.89 & 0.0246 & -7.689 & 0.1752 & -43.860 .0145 \\
\hline $1 L$ by $2 L$ & $x_{1} \cdot x_{2}$ & 13.02 & 1.123 & 11.60 & 0.0547 & -2.264 & 0.1887 & -12.000 .0529 \\
\hline $1 L$ by $3 L$ & $x_{1} \cdot x_{3}$ & -11.09 & 1.122 & -9.881 & 0.0642 & 0.6271 & 0.1886 & 3.3250 .1860 \\
\hline $2 L$ by $3 L$ & $x_{2} \cdot x_{3}$ & 15.22 & 1.122 & 13.57 & 0.0468 & -3.138 & 0.1886 & -16.640 .0382 \\
\hline
\end{tabular}

Italic values indicate significance of $p$ value $(p<0.05)$

$L$-linear main effects of input values

$Q$-square main effects of input values

$1 L$ by $2 L$ linear interactions effects between $C_{0}$ and $m$

$1 L$ by $3 L$ linear interactions effects between $C_{0}$ and $\mathrm{pH}$

$2 L$ by $3 L$ linear interactions effects between $\mathrm{m}$ and $\mathrm{pH}$
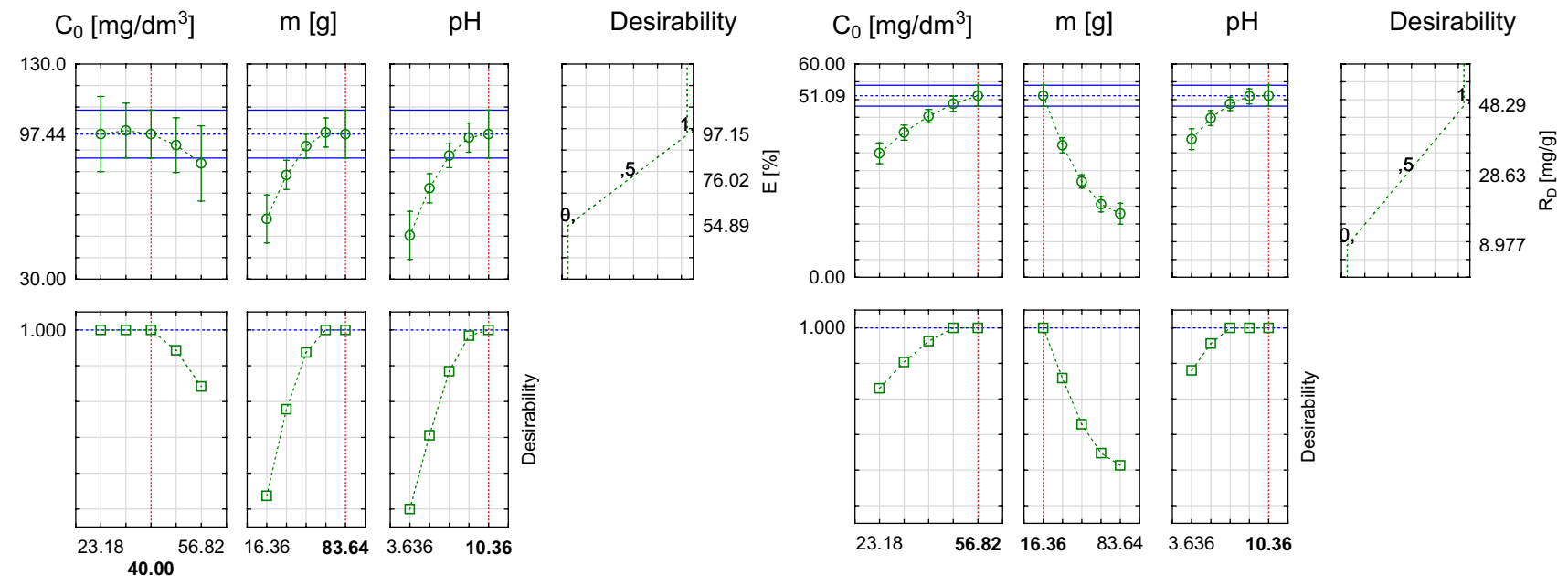

Fig. 6 Optimization plot for the removal of $\mathrm{MB}$ by $\mathrm{ZrO}_{2}-\mathrm{ZnO}\left(10 \% \mathrm{ZrO}_{2}\right)$

by the pollutant molecules rather than the catalyst, and this reduces catalytic efficiency. For the degree of dye removal, constant bed weight and higher MB concentration increases the concentration gradient of active reagents. A greater driving force improves the degree of dye removal from the solution. Similar results were obtained by investigating the effectiveness of ultrasonicated $\mathrm{ZnO}-\mathrm{ZrO}_{2}$ on another dye, congo red (Aghabeygi and Khademi-Shamami 2018), and by testing $\mathrm{MB}$ on $\mathrm{ZnO}$ modified $\mathrm{SnO}_{2}$ (Lin et al. 2018).

The effect of photocatalyst content on the photocatalytic performance The amount of catalyst was one of the most effec- tive parameters in the degradation studies. This was due to the increase in the number of $\mathrm{ZnO}$ particles, which increased the adsorption of photons and adsorption of pollutant molecules. On the other hand, the concentration gradient between the bed and the dye was the highest for $10 \mathrm{mg}$ of the bed. The degree of dye removal, unlike efficiency, is referred to a unit mass of the bed used, hence an increase in the amount of $\mathrm{ZrO}_{2}-\mathrm{ZnO}$ causes a decrease in the use of the bed surface. It has been observed that with the increase of $\mathrm{ZrO}_{2}-\mathrm{ZnO}(10-90 \mathrm{mg})$, the efficiency of the deposit increases, which is in contrast to the degree of dye removal. With a higher amount of photocatalyst mass, the number of free electron-hole pairs increases, there- 


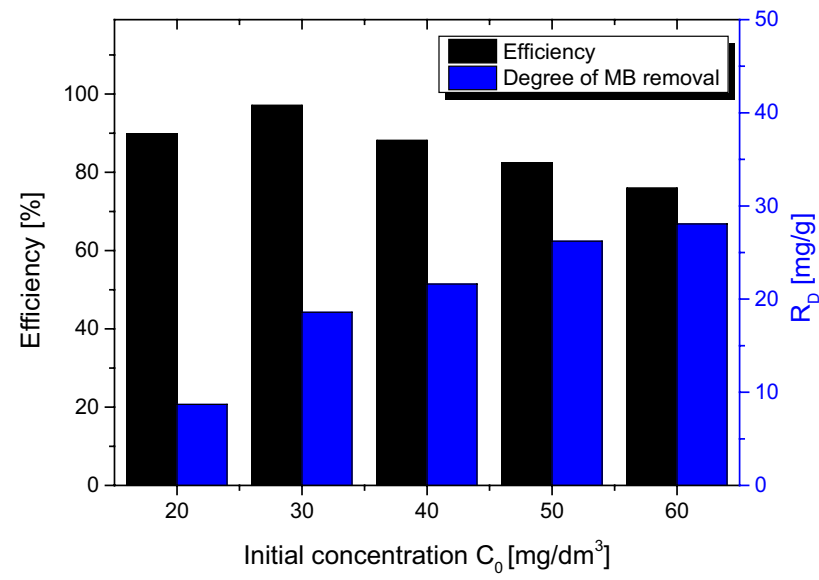

Fig. 7 Effect of the initial concentration of $M B$ solution on the efficiency and photodegradation of $\mathrm{MB}$ on $\mathrm{ZrO}_{2}-\mathrm{ZnO}$ ( $m=50 \mathrm{mg}, \mathrm{pH}=7$ )

fore, more particles of the dye are removed. However, not all active spaces of the $\mathrm{ZrO}_{2}-\mathrm{ZnO}$ are used (Fig. 8). In the case of deposit efficiency, the concentration gradient increases, which results in a higher degree of dye removal without this being converted into a unitary amount of dye in the solution.

Effect of the initial $\mathrm{pH}$ of the dye solution on photocatalytic performance At the acidic $\mathrm{pH}$ of the solution, the lowest degree of oxidation and the lowest degree of dye removal from the solution were observed (Fig. 9). Spathis and Poulious showed that in aqueous solutions, under the influence of UV irradiation, $\mathrm{ZnO}$ can undergo partial dissolution, which is known as photocorrosion (Spathis and Poulios 1995). In an acidic environment, it can proceed as follows:

$2 \mathrm{ZnO}+2 \mathrm{H}^{+}+2 \mathrm{~h}_{\mathrm{VB}}^{+} \rightarrow \mathrm{H}_{2} \mathrm{O}_{2}+\mathrm{Zn}^{2+}$.

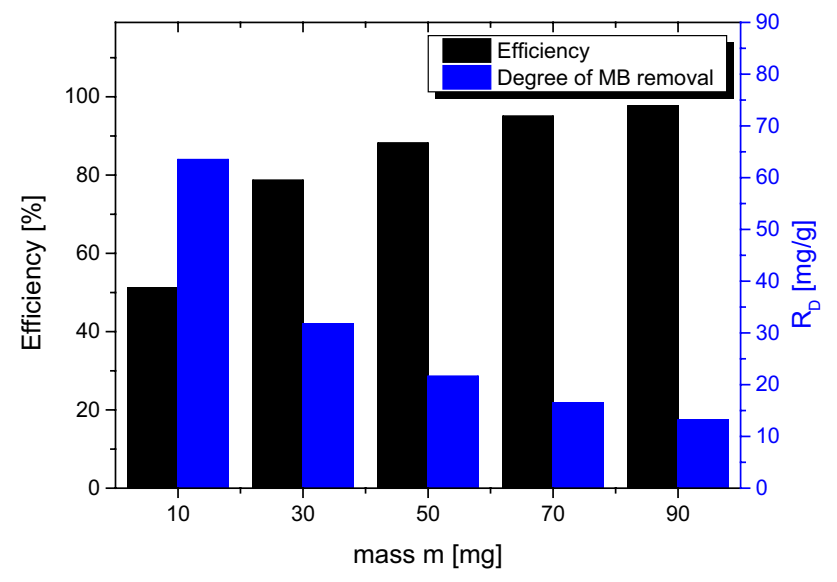

Fig. 8 Effect of mass on efficiency and photodegradation of $\mathrm{MB}$ on $\mathrm{ZrO}_{2}-\mathrm{ZnO}\left(C_{0}=40 \mathrm{mg} / \mathrm{dm}^{3}, \mathrm{pH}=7\right)$

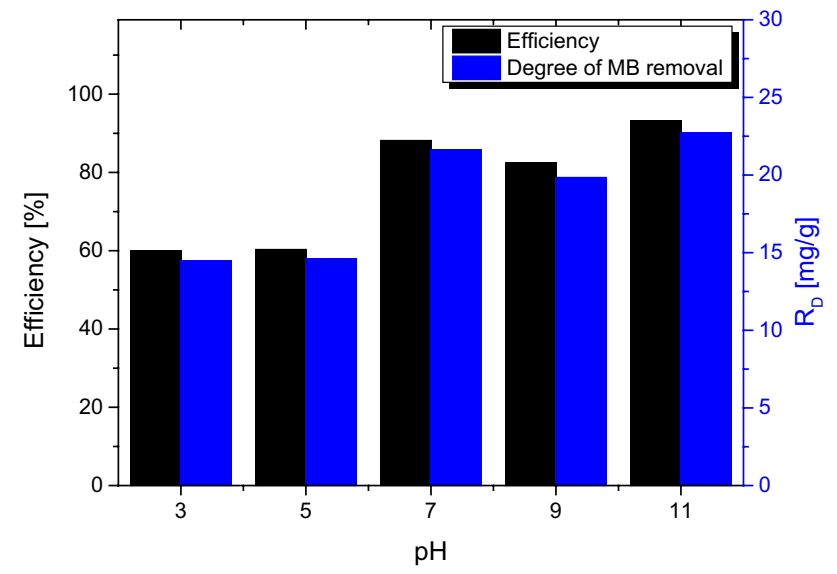

Fig. 9 Effect of solution $\mathrm{pH}$ on efficiency and photodegradation of $\mathrm{MB}$ on $\mathrm{ZrO}_{2}-\mathrm{ZnO}\left(C_{0}=40 \mathrm{mg} / \mathrm{dm}^{3}, \mathrm{~m}=50 \mathrm{mg}\right)$

This results in a double inhibition of the photocatalytic activity of the material. First, it reduces the amount of zinc oxide that would generate electron-hole pairs. Additionally, a part of $\mathrm{h}_{\mathrm{VB}}^{+}$, instead of participating in the generation of $\mathrm{H}$, can participate in the competitive $\mathrm{ZnO}$ oxidation reaction and thus reduce the overall efficiency of the photocatalytic process. In solutions with a higher $\mathrm{pH}$ near the $\mathrm{Zn}^{2+}$ ions, mainly $\mathrm{H}_{2} \mathrm{O}$ and $\mathrm{OH}^{-}$ions $\left(\mathrm{H}_{2} \mathrm{O}_{\text {ads }}, \mathrm{OH}_{\text {ads }}^{-}\right)$ are absorbed. They can be oxidised by $\mathrm{h}_{\mathrm{VB}}^{+}$, which is generated under the influence of UV radiation (Aghabeygi and Khademi-Shamami 2018). The $\mathrm{OH}$ radicals can participate in further free radical reactions with dye particles adsorbed on the $\mathrm{ZnO}$ surface. This leads to the degradation of organic compounds:

dye $+\mathrm{OH}^{\cdot} \rightarrow$ decomposition products.

\section{Kinetic studies, effect of time on photocatalytic performance}

In the general approach, the mechanism of photocatalytic degradation follows the Langmuir-Hinshelwood (L-H) kinetic model (Lee et al. 2015). The L-H model was used to investigate the effect of time on the heterogeneous photodegradation process and the equation of reaction rate $(r)$ is represented by

$r=\frac{K_{1} K_{2} C}{1+K_{2} C}$

where $K_{1}$ is the rate constant, which includes various parameters such as nanophotocatalyst content, and $K_{2}$ is the adsorption constant. After assuming that the dye concentration is low, $K_{2} C \ll 1$, hence the reaction rate is a 
first-order equation (Aghabeygi and Khademi-Shamami 2018). Taking into account the boundary conditions $\left[C=C_{0}\right.$ at $t$ (time) $=0$ ], it is possible to determine the reaction rate constant:

$-\ln \frac{C}{C_{0}}=k t$,

where $k$ is the photodegradation rate constant $\left(\min ^{-1}\right)$.

A series of tests were carried out where the concentration of the dye in the solution was examined at a concentration of MB $40 \mathrm{mg} / \mathrm{dm}^{3}$ with $500 \mathrm{mg}$ of photocatalyst in $300 \mathrm{ml}$ of mixture. The results are shown in Fig. 10. For the first $30 \mathrm{~min}$, to establish the equilibrium, the process was carried out in darkness. After selected intervals, a sample was taken to examine the concentration of the dye. The convex curve indicates a decreasing amount of dye in the mixture and, consequently, the dye particles are degraded with a lower rate. It can be seen from Fig. 10b that the kinetic experimental data are in good agreement with the kinetic model $\left(R^{2}=0.9925\right)$ and the first-order rate constant equals $0.03324 \mathrm{~min}^{-1}$. Belcha et al. examined the effect of catalyst concentration on the MB degradation rate over time. They determined rate constants of $0.0124 \mathrm{~min}^{-1}$ for $\mathrm{ZnO}$ NPs obtained using the sol-gel method and $0.0084 \mathrm{~min}^{-1}$ for ZnO NPs obtained using the precipitation method (Balcha et al. 2016). Payra et al. investigated the photocatalytic degradation mechanism of MB over ZIF-derived $\mathrm{ZnO}$, obtaining first-order kinetics and a rate constant of $0.0452 \mathrm{~min}^{-1}$, which confirmed the efficiency of the photocatalytic material (Payra et al. 2019).

(A)

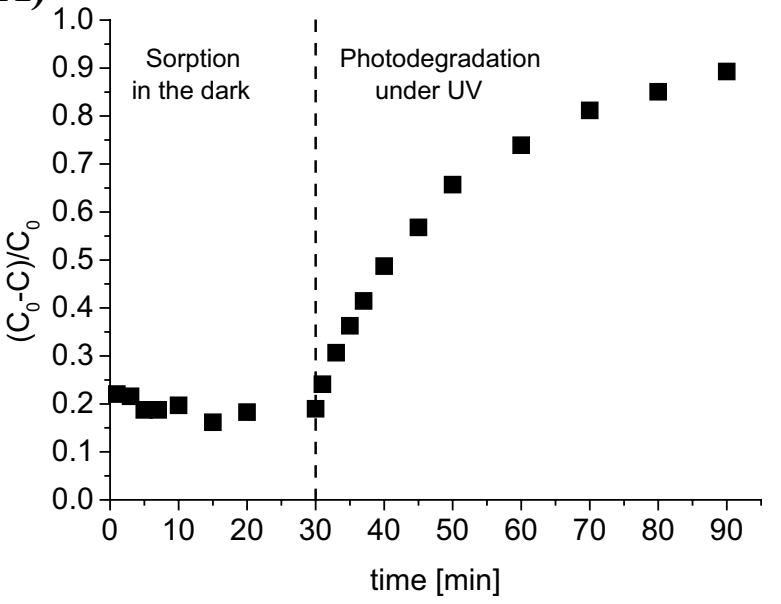

\section{Characterization}

TEM-EDX investigations TEM analysis confirms that $\mathrm{ZrO}_{2}-$ $\mathrm{ZnO}$ NPs preserve their original structure after sorption and photocatalytic processes (Fig. 11a-f). Different types of particles were obtained. Long needle-shaped microparticles as well as their nanoscale counterparts were observed (Fig. 11a, c, e). At the same time, irregularly shaped nanoparticles consisting of crystallites of several nanometers appear on the surface of other particles (Fig. 11b, d, f). An EDX analysis was also carried out to confirm the elemental composition of the obtained composite (Fig. 12). The EDX analysis confirmed the presence of all three elements: $\mathrm{Zr}, \mathrm{Zn}$ and $\mathrm{O}$. It can be seen that in the first area of scanning, there are sharp peaks from zinc and oxygen indicating the presence of $\mathrm{ZnO}$, however, there are no visible reflexes from zirconium. In contrast to the first area, in the second scanning region, clear peaks are visible from both zinc and zirconium as well as oxygen, which confirms the presence of $\mathrm{ZrO}_{2}$ and $\mathrm{ZnO}$. Depending on the place of sample analysis, the material composition differs from 0.54 to $24.41 \%_{\mathrm{wt}}$ $\mathrm{ZrO}_{2}$. Compared to the results, the percentage composition of the XRD analysis was $10-11 \%{ }_{\mathrm{wt}} \mathrm{ZrO}_{2}$. A discrepancy in the results indicates the inhomogeneity of the material in the nanoscale, nonetheless, it was expected that both the use of powdered $\mathrm{ZrO}_{2}$ and the use of only $10 \%$ of $\mathrm{ZrO}_{2}$ on the whole mass would prevent a homogeneous material for the entire volume from being obtained.

XRD investigations XRD analysis confirmed that zinc oxide in crystalline form and amorphous zirconium oxide had been obtained. Materials after sorption and photodegradation processes did not change their form. Figure 13 shows the XRD patterns of the synthesized pure $\mathrm{ZnO}, \mathrm{ZrO}_{2}$ and

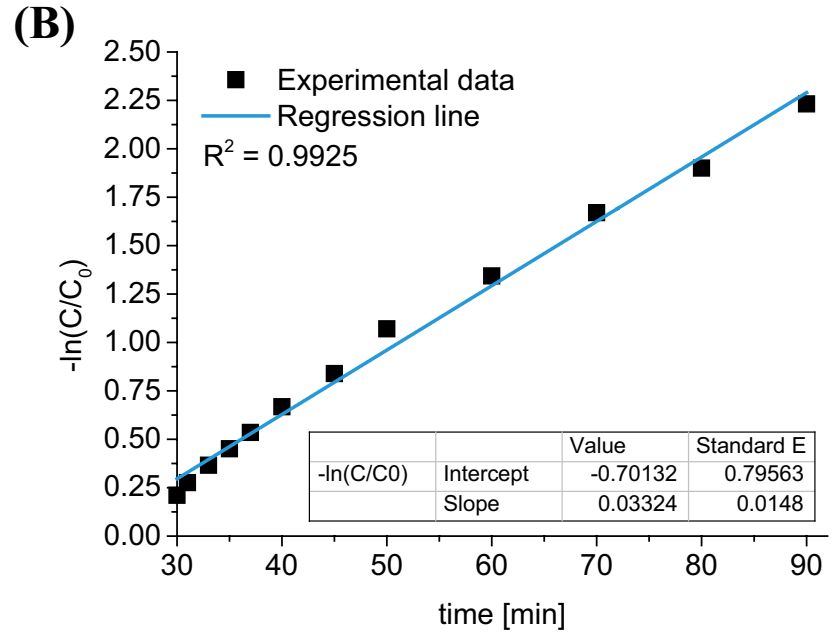

Fig. 10 Absorption of MB in different exposure times under UV radiation (a); kinetics of photocatalyst degradation of MB under UV radiation (b)

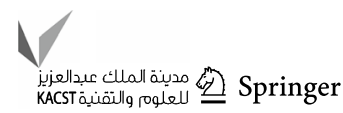




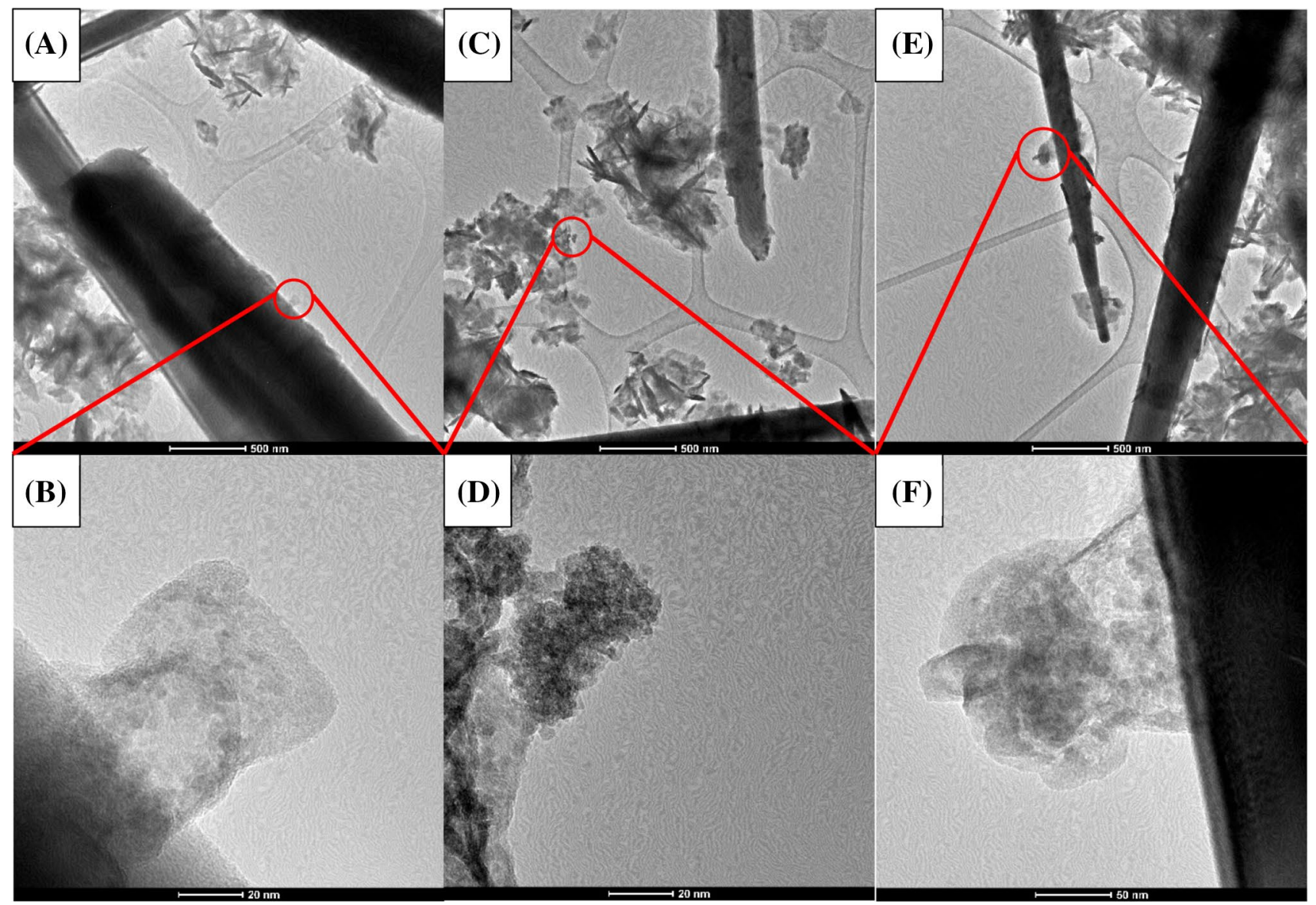

Fig. 11 TEM images of the $\mathrm{ZrO}_{2}-\mathrm{ZnO}$ nanoparticles: pure $\mathrm{ZrO}_{2}-\mathrm{ZnO}(\mathbf{a}, \mathbf{b})$, after the sorption process (c, d), after the photocatalytic process (e, f)
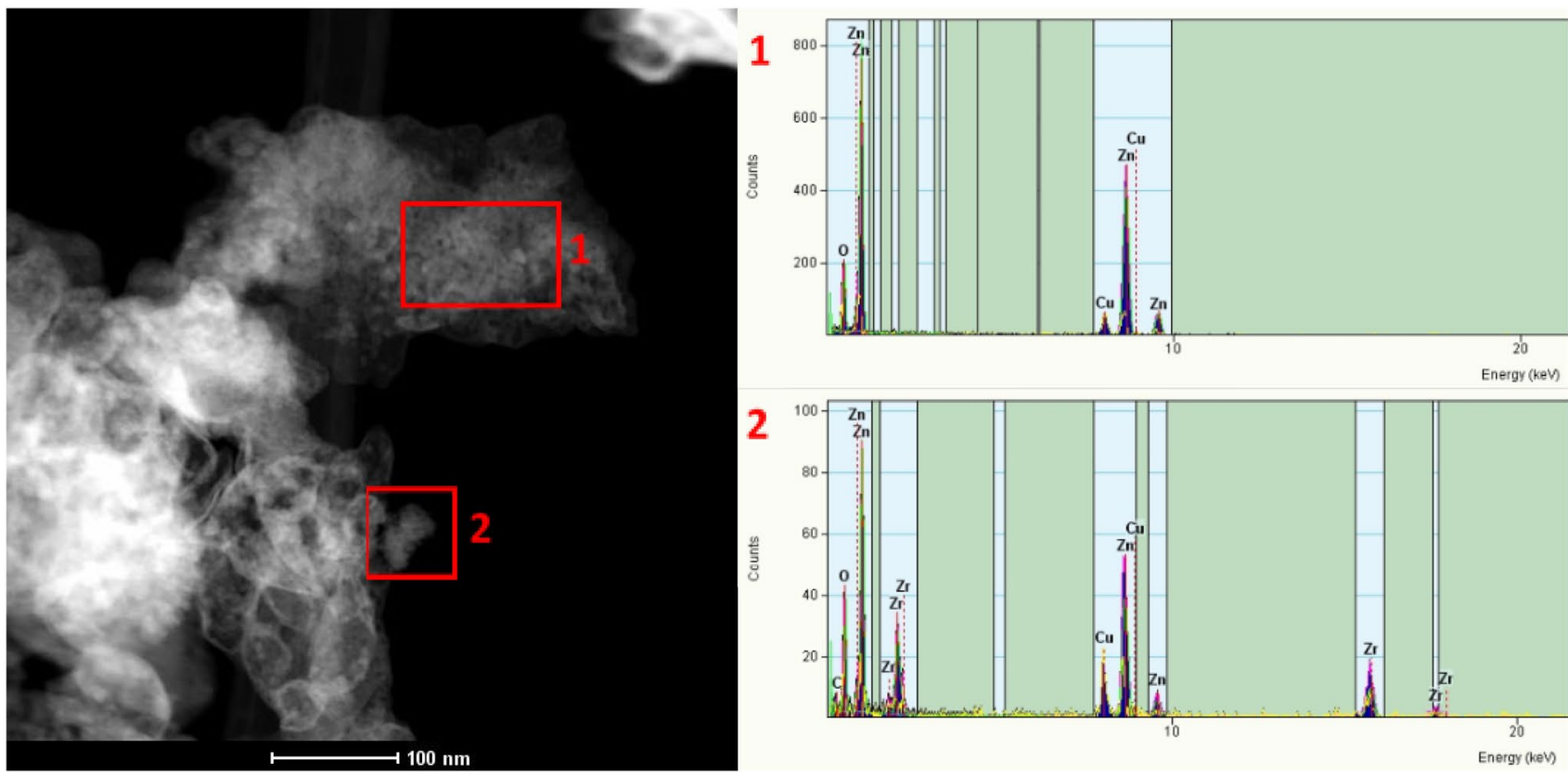

Fig. 12 TEM-EDX images of the $\mathrm{ZrO}_{2}-\mathrm{ZnO}$ nanoparticles

1.

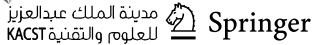




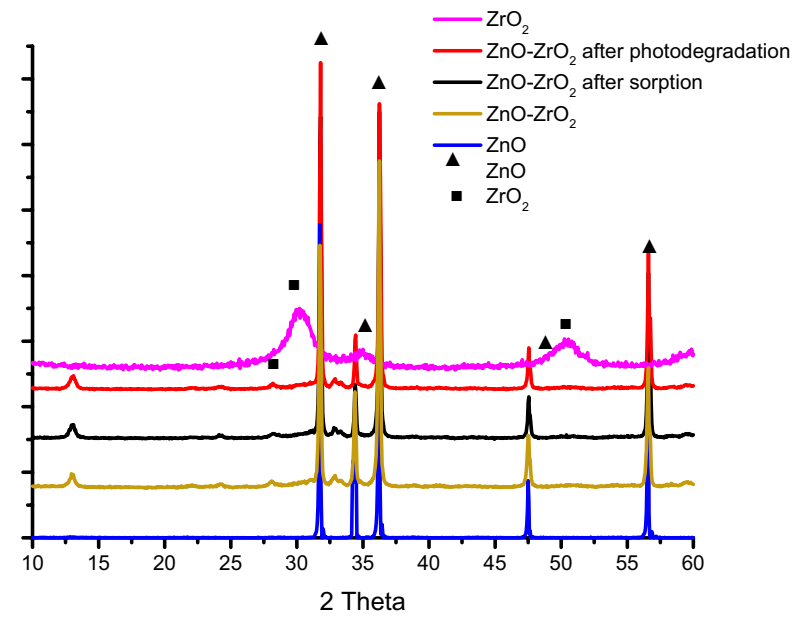

Fig. $13 \mathrm{XRD}$ pattern of $\mathrm{ZnO}, \mathrm{ZrO}_{2}$, and $\mathrm{ZrO}_{2}-\mathrm{ZnO}$ (10\%) before and after sorption and photodegradation processes

$\mathrm{ZrO}_{2}-\mathrm{ZnO}(10 \%)$ before and after the sorption process and the photodegradation of the MB. The XRD pattern of the prepared crystalline $\mathrm{ZnO}$ is in accordance with the hexagonal zincite crystalline structure of $\mathrm{ZnO}$, with sharp and strong peaks at $2 \theta \mathrm{s}$ of $31.75^{\circ}, 34.40^{\circ}, 36.24^{\circ}, 47.54^{\circ}$ and $56.61^{\circ}$, which correspond to (100), (002), (101), (012) and (110), respectively (Garino et al. 2019; Hasanpoor et al. 2015). The XRD pattern for pure $\mathrm{ZrO}_{2}$ confirmed characteristic planes at $2 \theta \mathrm{s}$ of $30.23^{\circ}, 34.92^{\circ}$ and $50.26^{\circ}$ (Singh and Nakate 2014; Manjunatha and Dharmaprakash 2016). The peak centred at $30.23^{\circ}$ (101) is characteristic of the tetragonal crystalline phase (Uribe López et al. 2019). In the $\mathrm{ZrO}_{2}-\mathrm{ZnO}$, the corresponding peaks of $\mathrm{ZrO}_{2}$ are absent, whereas peaks corresponding to the $\mathrm{ZnO}$ remain sharp and strong. In addition, the diffractograms representing $\mathrm{ZnO}-$ $\mathrm{ZrO}_{2}$ show less homogeneous patterns compared to pure $\mathrm{ZnO}$, which indicates an increased amorphous structure. The patterns suggest a greater polydispersity of the material surface, thanks to which the material has better photocatalytic properties.

FTIR results The FT-IR spectra of pure $\mathrm{ZnO}$, pure $\mathrm{ZrO}_{2}$ and $\mathrm{ZnO}-\mathrm{ZrO}_{2}$ nanoparticles are presented in Fig. 14. All materials show spectra at a wavenumber of about $500 \mathrm{~cm}^{-1}$, which indicates the metal-oxygen bonding of $\mathrm{Zn}-\mathrm{O}$ and $\mathrm{Zr}-\mathrm{O}$ (Janaki et al. 2015). The peaks at around $3400 \mathrm{~cm}^{-1}$ and $1500 \mathrm{~cm}^{-1}$ in all samples are the stretching and bending vibrational bands of the hydroxyl groups adsorbed on the surface. These effects from hydroxyl groups are strongly visible due to the lack of calcination of the obtained products. At the same time, it should be noted that these interactions are more pronounced for samples with $\mathrm{ZrO}_{2}$, which is related to the amorphous nature of these products and the formation of bonds between $\mathrm{O}-\mathrm{H}$ and $\mathrm{Zr}-\mathrm{O}$ (Zinatloo-

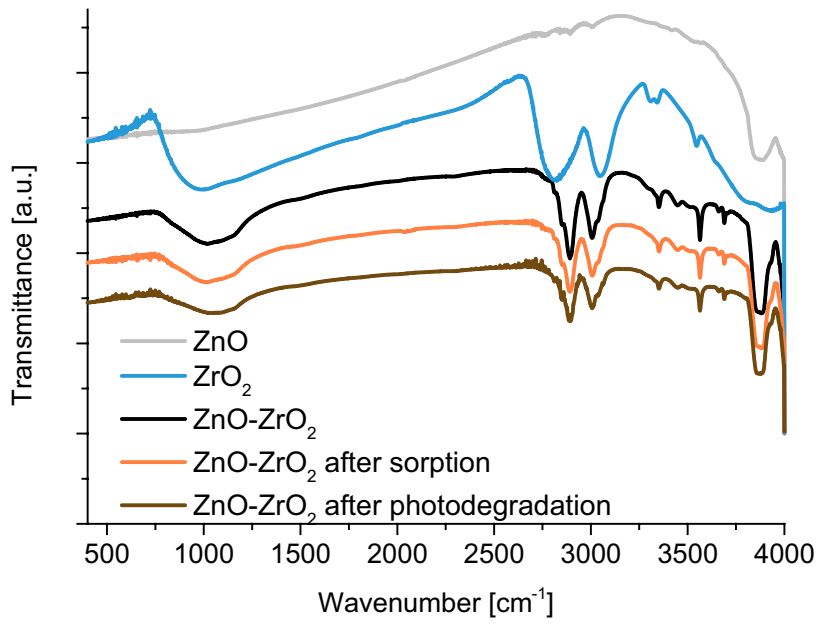

Fig. 14 FT-IR spectra of $\mathrm{ZnO}, \mathrm{ZrO}_{2}$, and $\mathrm{ZrO}_{2}-\mathrm{ZnO}\left(10 \% \mathrm{ZrO}_{2}\right)$ before and after sorption and photodegradation processes

Ajabshir and Salavati-Niasari 2016). The sharp signals in the region of $1360-1420 \mathrm{~cm}^{-1}$ appear from carbonate anions, which is a direct result of the use of sodium carbonate as a precipitating agent (Khan et al. 2016). There are no visible peaks derived from adsorbed $\mathrm{MB}$ at 1390,1487 or $1590 \mathrm{~cm}^{-1}$ (Bartošová et al. 2017) in the $\mathrm{ZnO}-\mathrm{ZrO}_{2}$ after the sorption process due to the fact that they coincide with the peaks from pure bed in the region of $1360-1600 \mathrm{~cm}^{-1}$, which in combination with a relatively small amount of adsorbed MB, causes them to be totally covered.

\section{Mechanism of photocatalyst}

The mechanism of dye photodegradation using a $\mathrm{ZnO}$ semiconductor initiated by UV can be presented in the following equation:

$\mathrm{ZnO}+h v \rightarrow \mathrm{ZnO}\left(\mathrm{h}_{\mathrm{vb}}^{+}+\mathrm{e}_{\mathrm{cb}}^{-}\right)$,

where $h_{v b}^{+}$are holes of the generated valence band of the semiconductor, which have strong oxidising properties, and $\mathrm{e}_{\mathrm{cb}}^{-}$are electrons generated in the conduction band of the semiconductor, which have high reducing properties (Uribe López et al. 2019).

The addition of semiconductors is one way of improving the photocatalytic properties of $\mathrm{ZnO}$. Different widths of energy bands occurring in both oxides contribute to reducing the distance between the conduction bands and the valence bands in the whole composite. In the $\mathrm{ZrO}_{2}-\mathrm{ZnO}$ system, some of the electrons pass from the conduction band of $\mathrm{ZrO}_{2}$ to the conduction band of $\mathrm{ZnO}$. At the same time, from the valence band of $\mathrm{ZnO}$, some of the holes migrate to the valence band of $\mathrm{ZrO}_{2}$, leading to the generation of electron-hole pairs (Fig. 15). Electron transfer, and consequently

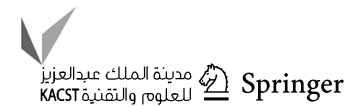




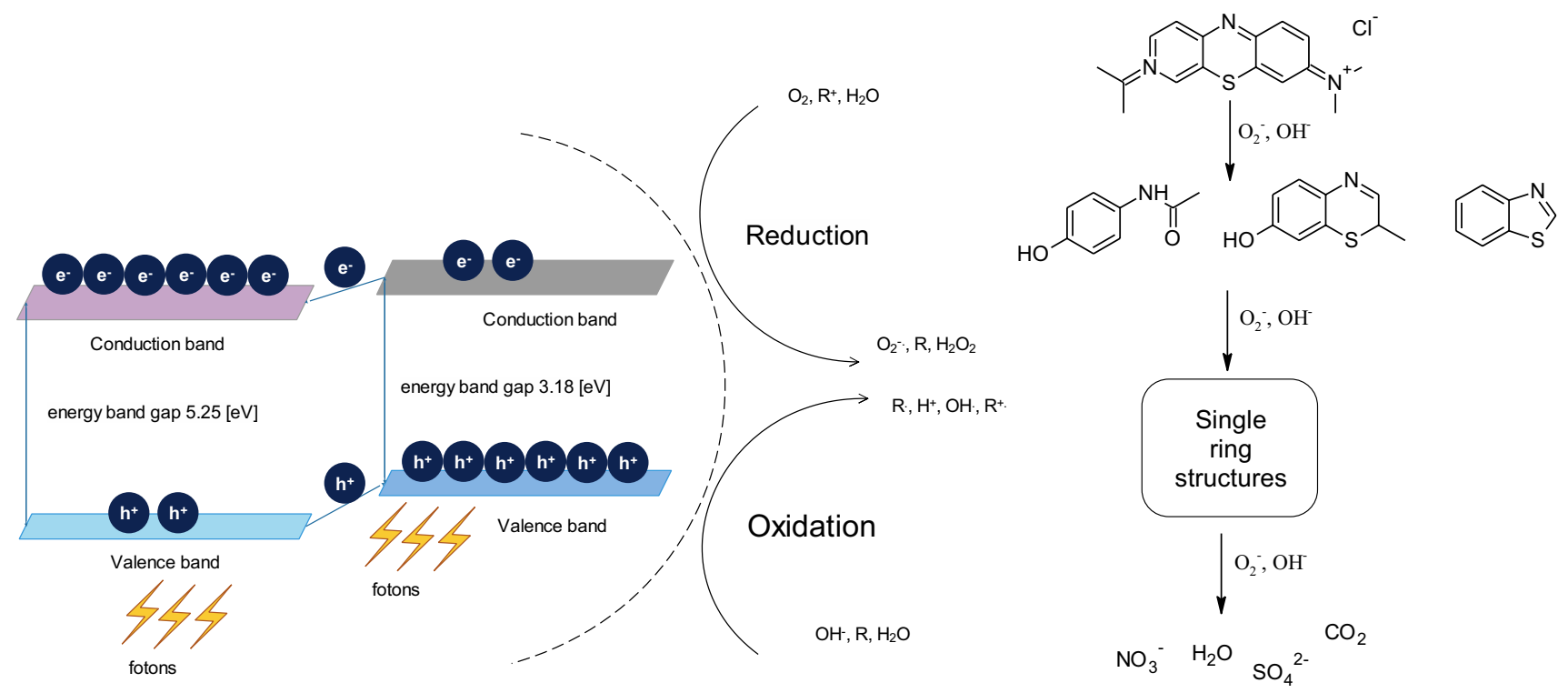

Fig. 15 Scheme of the photocatalytic mechanism of the electron-hole pair separation of $\mathrm{ZrO}_{2}-\mathrm{ZnO}$ nanoparticles in the degradation of $\mathrm{MB}$

the transfer of holes, contributes to the reduction of the rate of recombination of the electron-hole pairs, a phenomenon that reduces photocatalytic efficiency (Aghabeygi and Khademi-Shamami 2018; Lin et al. 2018).

The photocatalytic decomposition of dye, in this case $\mathrm{MB}$, takes place in stages. Radicals and ions obtained in the photocatalytic process cause the dye to degrade in a multistep process. In the initial stages, the least stable bonds decay, resulting in single ring compounds, which in the final stage become basic inorganic compounds like $\mathrm{H}_{2} \mathrm{O}$, $\mathrm{CO}_{2}, \mathrm{NO}_{3}^{-}$and $\mathrm{SO}_{4}^{2-}$ (Adeleke et al. 2018).

\section{Effect of type of dye on photocatalytic performance}

The efficiency of photocatalytic processes depends not only on photocatalyst properties but also on effluent composition, including the type of removed dye. The effect of the composition of the dye mixture on the photocatalytic properties of the deposit was investigated by studies of the photodegradation of a mixture of Methyl Orange (MO) and MB (MB) dye. The UV-Vis spectra of the solutions of the dyes after 30 min of photodegradation are shown in Fig. 16. Based on the UV-Vis spectra, the characteristic wavelengths for each dye were chosen: $464 \mathrm{~nm}$ for MO and $664 \mathrm{~nm}$ for MB. Analysis of the results showed a much higher amount of degraded MB compared to MO. The amount of degraded $\mathrm{MB}$, which is a cationic dye, remained at $90 \%$, while the amount of degraded MO did not exceed $70 \%$ (Table 6).

The higher efficiency of $\mathrm{MB}$ removal may result from the presence of an increased amount of $\cdot \mathrm{OH}$ and $\mathrm{OH}^{-}$ groups on the surface of $\mathrm{ZrO}_{2}-\mathrm{ZnO}$, which interact with positively charged MB ions and cause their decomposition

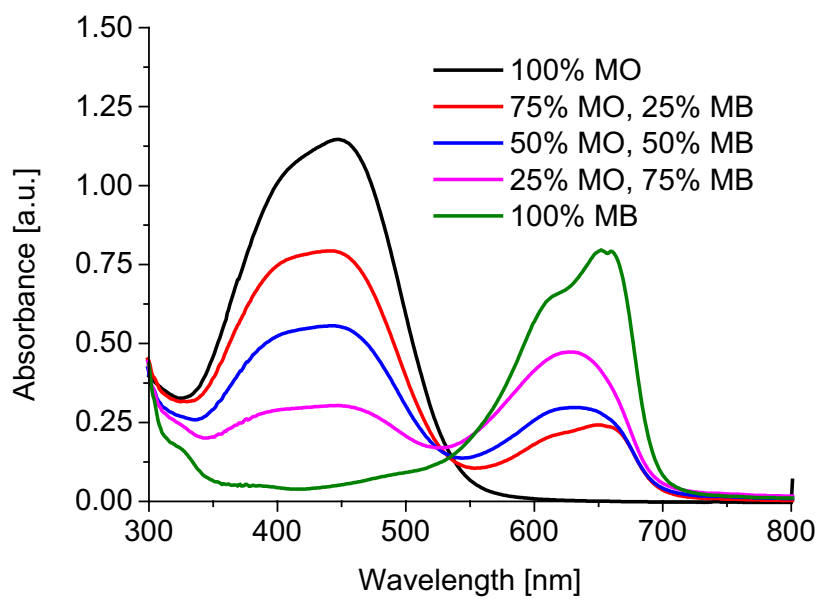

Fig. 16 Interference by mixture of dyes evaluated by UV-Vis spectra after 30 min of photodegradation of solutions of MO and MB in different mass concentrations of each dye: (pure MO) $40 \mathrm{mg} / \mathrm{dm}^{3}, 75 \%$ $\mathrm{MO}-25 \% \mathrm{MB}, 50 \% \mathrm{MO}-50 \% \mathrm{MB}, 25 \% \mathrm{MO}-75 \% \mathrm{MB}$, (pure MB) $40 \mathrm{mg} / \mathrm{dm}^{3}$

rather than the anionic dye. Similar conclusions have been reached by Trandafilović et al. among others, who investigated the effect of the dye type on the efficiency of a $\mathrm{ZnO}-\mathrm{Eu}$ deposit. They confirmed higher MB removal compared to MO. They also confirmed the significant effect of the presence of $\mathrm{OH}$ groups during the removal of $\mathrm{MB}$, while for $\mathrm{MO}$, the most important factor was the formation of holes (Trandafilović et al. 2017). Beura and Thangadurai studied the degradation efficiency of the $\mathrm{Sn}-\mathrm{ZnO}-$ graphene for mixed dyes (MO and $\mathrm{MB}$ ). $17 \%$ of MO was degraded under UV, whereas MB was 
Table 6 Amount of degraded dyes (MB, MO), separated and combined in different proportions

\begin{tabular}{|c|c|c|c|}
\hline \multirow[t]{2}{*}{ Composition of dyes mixture } & \multicolumn{2}{|c|}{$\begin{array}{l}\text { The amount of the } \\
\text { degraded dye } R_{\mathrm{D}}(\mathrm{mg} / \mathrm{g})\end{array}$} & \multirow[t]{2}{*}{$\begin{array}{l}\text { The total amount of the } \\
\text { degraded dyes }(\mathrm{mg} / \mathrm{g})\end{array}$} \\
\hline & MB & MO & \\
\hline Methylene Blue $40 \mathrm{mg} / \mathrm{dm}^{3}$ & 21.84 & - & 21.84 \\
\hline $75 \% \mathrm{MB}\left(30 \mathrm{mg} / \mathrm{dm}^{3}\right)+25 \% \mathrm{OM}\left(10 \mathrm{mg} / \mathrm{dm}^{3}\right)$ & 17.28 & 3.70 & 20.98 \\
\hline $50 \% \mathrm{MB}\left(20 \mathrm{mg} / \mathrm{dm}^{3}\right)+50 \%$ OM $\left(20 \mathrm{mg} / \mathrm{dm}^{3}\right)$ & 11.58 & 7.57 & 19.15 \\
\hline $25 \% \mathrm{MB}\left(10 \mathrm{mg} / \mathrm{dm}^{3}\right)+75 \% \mathrm{OM}\left(30 \mathrm{mg} / \mathrm{dm}^{3}\right)$ & 5.62 & 11.57 & 17.19 \\
\hline Methyl Orange $40 \mathrm{mg} / \mathrm{dm}^{3}$ & - & 10.65 & 10.65 \\
\hline
\end{tabular}

simultaneously degraded with $78 \%$ efficiency under UV (Beura and Thangadurai 2018).

\section{Conclusions}

$\mathrm{ZnO}$ crystallites were successfully synthesised with different amounts of $\mathrm{ZrO}_{2}$ via a precipitation method with the help of microwave irradiation. Results showed that the addition of $\mathrm{ZrO}_{2}$ significantly increased the photocatalytic properties of $\mathrm{ZnO}$. Different widths of energy bands occurring in both oxides contributed to reducing the distance between the conduction bands and the valence bands in the whole composite. An increase in the mass of the bed, an increase in the $\mathrm{pH}$ of the solution, and a decrease in the initial concentration of $\mathrm{MB}$ caused the photocatalytic efficiency of $\mathrm{ZrO}_{2}-\mathrm{ZnO}$ to be over $97 \%$ after just $30 \mathrm{~min}$. The photocatalytic activity of cationic dye $\mathrm{MB}$ was greater than the photodegradation of anionic dye MO.

Funding This research did not receive any specific grant from funding agencies in the public, commercial, or not-for-profit sector.

\section{Compliance with ethical standards}

Conflict of interest The authors report no declarations of interest.

Open Access This article is distributed under the terms of the Creative Commons Attribution 4.0 International License (http://creativeco mmons.org/licenses/by/4.0/), which permits unrestricted use, distribution, and reproduction in any medium, provided you give appropriate credit to the original author(s) and the source, provide a link to the Creative Commons license, and indicate if changes were made.

\section{References}

Adeleke JT, Theivasanthi T, Thiruppathi M, Swaminathan M, Akomolafe T, Alabi AB (2018) Photocatalytic degradation of methylene blue by $\mathrm{ZnO} / \mathrm{NiFe}_{2} \mathrm{O}_{4}$ nanoparticles. Appl Surf Sci 455:195-200. https://doi.org/10.1016/J.APSUSC.2018.05.184

Aghabeygi S, Khademi-Shamami M (2018) $\mathrm{ZnO} / \mathrm{ZrO}_{2}$ nanocomposite: sonosynthesis, characterization and its application for wastewater treatment. Ultrasonics Sonochem 41:458-465. https ://doi.org/10.1016/j.ultsonch.2017.09.020

Aghabeygi S, Sharifi Z, Molahasani N (2017) Enhanced photocatalytic property of nano- $\mathrm{ZrO}_{2}-\mathrm{SnO}_{2} \mathrm{NPs}$ for photodegradation of an azo dye. Digest J Nanomater Biostruct 12. http://www.chalc ogen.ro/81_AghabeygiS.pdf. Accessed 4 Sept 2019

Al-Hamdi AM, Sillanpää M, Dutta J (2015) Gadolinium doped tin dioxide nanoparticles: an efficient visible light active photocatalyst. J Rare Earths 33(12):1275-1283. https://doi.org/10.1016/ S1002-0721(14)60557-3

Balcha A, Yadav OP, Dey T (2016) Photocatalytic degradation of methylene blue dye by zinc oxide nanoparticles obtained from precipitation and sol-gel methods. Environ Sci Pollut Res 23:2548525493. https://doi.org/10.1007/s11356-016-7750-6

Bartošová A, Blinová L, Sirotiak M, Michalíková A (2017) Usage of FTIR-ATR as non-destructive analysis of selected toxic dyes. Res Pap Fac Mater Sci Technol Slovak Univ Technol 25:103-111. https://doi.org/10.1515/rput-2017-0012

Beura R, Thangadurai P (2018) Effect of Sn doping in $\mathrm{ZnO}$ on the photocatalytic activity of $\mathrm{ZnO}$-graphene nanocomposite with improved activity. J Environ Chem Eng 6:5087-5100. https://doi. org/10.1016/J.JECE.2018.07.049

Chen X, Zhang F et al (2015) The synthesis of $\mathrm{ZnO} / \mathrm{SnO}_{2}$ porous nanofibers for dye adsorption and degradation. Dalton Trans 44:3034-3042. https://doi.org/10.1039/C4DT03382E

Dal Santo V, Naldoni A, Dal Santo V, Naldoni A (2018) Titanium dioxide photocatalysis. Catalysts 8:591. https://doi.org/10.3390/ catal8120591

Garino N, Limongi T et al (2019) A microwave-assisted synthesis of zinc oxide nanocrystals finely tuned for biological applications. Nanomaterials 9:212. https://doi.org/10.3390/nano9020212

Gurushantha K, Renuka L et al (2017) Photocatalytic and photoluminescence studies of $\mathrm{ZrO}_{2} / \mathrm{ZnO}$ nanocomposite for LED and Waste water treatment applications. Mater Today Proc 4:11747-11755. https://doi.org/10.1016/j.matpr.2017.09.091

Hasanpoor M, Aliofkhazraei M, Delavari H (2015) Microwave-assisted synthesis of zinc oxide nanoparticles. Procedia Mater Sci 11:320 325. https://doi.org/10.1016/J.MSPRO.2015.11.101

Ibrahim MM (2015) Photocatalytic activity of nanostructured $\mathrm{ZnO}$ $\mathrm{ZrO}_{2}$ binary oxide using fluorometric method. Spectrochim Acta Part A Mol Biomol Spectrosc 145:487-492. https://doi. org/10.1016/j.saa.2015.02.057

Janaki AC, Sailatha E, Gunasekaran S (2015) Synthesis, characteristics and antimicrobial activity of $\mathrm{ZnO}$ nanoparticles. Spectrochim Acta Part A Mol Biomol Spectrosc 144:17-22. https://doi. org/10.1016/J.SAA.2015.02.041

Karuppaiah S, Annamalai R et al (2019) Efficient photocatalytic degradation of ciprofloxacin and bisphenol A under visible light using $\mathrm{Gd}_{2} \mathrm{WO}_{6}$ loaded $\mathrm{ZnO} /$ bentonite nanocomposite. Appl Surf Sci 481:1109-1119. https://doi.org/10.1016/j.apsusc.2019.03.178 
Khan SA, Khan SB, Asiri AM, Ahmad I (2016) Zirconia-based catalyst for the one-pot synthesis of coumarin through Pechmann reaction. Nanoscale Res Lett. https://doi.org/10.1186/s11671-016-1525-3

Kokorin AI, Sviridova TV et al (2018) Structure and photocatalytic properties of $\mathrm{TiO}_{2} / \mathrm{MoO}_{3}$ and $\mathrm{TiO}_{2} / \mathrm{V}_{2} \mathrm{O}_{5}$ nanocomposites obtained by mechanochemical activation. Russ J Phys Chem B 12:330-335. https://doi.org/10.1134/S1990793118020173

Lakshmi C, Ananda S, Rudrappa S, Ranganathaiah C (2012) Synthesis of $\mathrm{ZnO} / \mathrm{ZrO}_{2}$ nanocomposites by electrochemical method and photocatalytic degradation of fast green dye, paper dyeing and printing press effluent. Int J Mater Sci 3:221-237

Lee KM, Abd Hamid SB, Lai CW (2015) Mechanism and kinetics study for photocatalytic oxidation degradation: a case study for phenoxyacetic acid organic pollutant. J Nanomater 2015:1-10. https://doi.org/10.1155/2015/940857

Lin J, Luo Z, Liu J, Li P (2018) Photocatalytic degradation of methylene blue in aqueous solution by using $\mathrm{ZnO}-\mathrm{SnO}_{2}$ nanocomposites. Mater Sci Semicond Process 87:24-31. https://doi.org/10.1016/J. MSSP.2018.07.003

Lu D, Gao Q, Wu X, Fan Y (2017) ZnO nanostructures decorated hollow glass microspheres as near infrared reflective pigment. Ceram Int 43:9164-9170. https://doi.org/10.1016/J.CERAM INT.2017.04.067

Manjunatha S, Dharmaprakash MS (2016) Microwave assisted synthesis of cubic zirconia nanoparticles and study of optical and photoluminescence properties. J Lumin 180:20-24. https://doi. org/10.1016/j.jlumin.2016.07.055

Mexicana De Física S, México AC et al (2007) Use of diffuse reflectance spectroscopy for optical characterization of un-supported nanostructures. Revista Mexicana De F Isica S 53. http://www. redalyc.org/articulo.oa?id=57028299004. Accessed 4 Sept 2019

Nagao T, Dao TD, Sugavaneshwar RP, Chen K, Nanda KK (2016) Effects of nanoscale morphology and defects in oxide: optoelectronic functions of zinc oxide nanowires. Radiat Eff Defects Solids 171:22-33. https://doi.org/10.1080/10420150.2016.1160906

Oluwabi AT, Acik IO, Katerski A, Mere A, Krunks M (2018) Structural and electrical characterisation of high- $\mathrm{ZrO}_{2}$ thin films deposited by chemical spray pyrolysis method. Thin Solid Films 662:129-136. https://doi.org/10.1016/J.TSF.2018.07.035

Payra S, Challagulla S, Bobde Y, Chakraborty C, Ghosh B, Roy S (2019) Probing the photo- and electro-catalytic degradation mechanism of methylene blue dye over ZIF-derived $\mathrm{ZnO}$. J Hazard Mater 373:377-388. https://doi.org/10.1016/J.JHAZM AT.2019.03.053

Pirzada BM, Mir NA, Qutub N, Mehraj O, Sabir S, Muneer M (2015) Synthesis, characterization and optimization of photocatalytic activity of $\mathrm{TiO}_{2} / \mathrm{ZrO}_{2}$ nanocomposite heterostructures. Mater Sci Eng B 193:137-145. https://doi.org/10.1016/J.MSEB.2014.12.005

Qiu L, Gong ZY, Li HL, Ouyang F (2018) Stably photocatalytic decomposition of rhodamine-B by samarium doped $\mathrm{ZrO}_{2}-\mathrm{ZnO}$ composite under simulant solar light irradiation. In: Proceedings of the 2018 international conference on energy development and environmental protection (EDEP 2018), Paris, France. Atlantis Press. https://doi.org/10.2991/edep-18.2018.2

Reszczyńska J, Grzyb T, Sobczak JW, Lisowski W, Gazda M, Ohtani B, Zaleska A (2015) Visible light activity of rare earth metal doped $\left(\mathrm{Er}^{3+}, \mathrm{Yb}^{3+}\right.$ or $\left.\mathrm{Er}^{3+} / \mathrm{Yb}^{3+}\right)$ titania photocatalysts. Appl Catal B 163:40-49. https://doi.org/10.1016/j.apcatb.2014.07.010

Ruiz-Hitzky E, Aranda P, Akkari M, Khaorapapong N, Ogawa M (2019) Photoactive nanoarchitectures based on clays incorporating $\mathrm{TiO}_{2}$ and $\mathrm{ZnO}$ nanoparticles. Beilstein J Nanotechnol 10:11401156. https://doi.org/10.3762/bjnano.10.114

Sapawe N, Jalil AA, Triwahyono S (2013) One-pot electro-synthesis of $\mathrm{ZrO}_{2}-\mathrm{ZnO} / \mathrm{HY}$ nanocomposite for photocatalytic decolorization of various dye-contaminants. Chem Eng J 225:254-265. https:// doi.org/10.1016/j.cej.2013.03.121

Singh AK, Nakate UT (2014) Microwave synthesis, characterization, and photoluminescence properties of nanocrystalline zirconia. Sci World J 2014:1-7. https://doi.org/10.1155/2014/349457

Sowik J, Miodyńska M et al (2019) Optical and photocatalytic properties of rare earth metal-modified $\mathrm{ZnO}$ quantum dots. Appl Surf Sci 464:651-663. https://doi.org/10.1016/J.APSUSC.2018.09.104

Spathis P, Poulios I (1995) The corrosion and photocorrosion of zinc and zinc oxide coatings. Corros Sci 37:673-680. https://doi. org/10.1016/0010-938X(95)80001-8

Thirumalai K, Shanthi M, Swaminathan M (2017) Synthesis and characterization of gadolinium tungstate doped zinc oxide photocatalyst. Indian J Chem Sect A Inorg Phys Theor Anal Chem 56A:50-56

Trandafilović LV, Jovanović DJ, Zhang X, Ptasińska S, Dramićanin MD (2017) Enhanced photocatalytic degradation of methylene blue and methyl orange by $\mathrm{ZnO}$ : Eu nanoparticles. Appl Catal B 203:740-752. https://doi.org/10.1016/J.APCATB.2016.10.063

Uribe López MC, Alvarez Lemus MA et al (2019) Synthesis and characterization of $\mathrm{ZnO}-\mathrm{ZrO}_{2}$ nanocomposites for photocatalytic degradation and mineralization of phenol. J Nanomater 2019:1-12. https://doi.org/10.1155/2019/1015876

Zinatloo-Ajabshir S, Salavati-Niasari M (2016) Facile route to synthesize zirconium dioxide $\left(\mathrm{ZrO}_{2}\right)$ nanostructures: structural, optical and photocatalytic studies. J Mol Liq 216:545-551. https://doi. org/10.1016/J.MOLLIQ.2016.01.062

Publisher's Note Springer Nature remains neutral with regard to jurisdictional claims in published maps and institutional affiliations. 